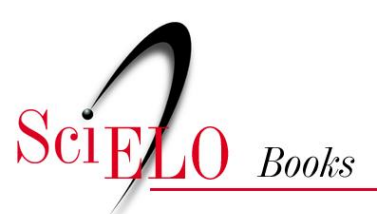

\title{
4. Morfologia externa dos adultos
}

\author{
Cleber Galvão \\ José Jurberg
}

\section{SciELO Books / SciELO Livros / SciELO Libros}

GALVÃO, C., and JURBERG, J. Morfologia externa dos adultos. In: GALVÃO, C., org. Vetores da doença de chagas no Brasil [online]. Curitiba: Sociedade Brasileira de Zoologia, 2014, pp. 33-39.

Zoologia: guias e manuais de identificação series. ISBN 978-85-98203-09-6. Available from SciELO Books $<$ http://books.scielo.org $>$.

\section{(2)(1)(2)}

All the contents of this chapter, except where otherwise noted, is licensed under a Creative Commons Attribution-Non Commercial-ShareAlike 3.0 Unported.

Todo o conteúdo deste capítulo, exceto quando houver ressalva, é publicado sob a licença Creative Commons Atribuição Uso Não Comercial - Partilha nos Mesmos Termos 3.0 Não adaptada.

Todo el contenido de este capítulo, excepto donde se indique lo contrario, está bajo licencia de la licencia Creative Commons Reconocimento-NoComercial-CompartirIgual 3.0 Unported. 


\section{Morfologia externa dos adultos}

(Cleber Galvão \& José Jurberg)

"Animais diferem uns dos outros em seus modos de subsistência, em suas ações, em seus hábitos e em suas partes."

(Aristóteles, História dos Animais, livro I)

Como comentado no capítulo 3, os hemípteros se caracterizam pelo aparelho bucal do tipo picador-sugador. Como os demais insetos possuem o corpo dividido em cabeça, tórax e abdômen e revestido por um exoesqueleto que é periodicamente substituído no processo conhecido como muda ou ecdise, permitindo assim o crescimento do inseto até a fase adulta. Os principais caracteres usados na diferenciação das famílias de hemípteros são as antenas, o rostro, as pernas e as asas. As antenas podem ter quatro ou cinco artículos; o rostro tem em geral três ou quatro artículos, e em alguns grupos repousa num sulco quando não está em uso. As pernas anteriores da maioria dos grupos predadores são adaptadas para agarrar a presa e são chamadas raptórias. Os hemélitros variam consideravelmente de acordo com cada grupo de hemípteros.

Na família Reduviidae a cabeça dos insetos é geralmente estreita e alongada, possui dois olhos compostos protuberantes separados dorsalmente por um espaço chamado região interocular (ou sinlipsis), e um sulco transversal pós-ocular. Logo após esse sulco estão localizados os ocelos que podem ser proeminentes ou mais achatados.

A região anterior aos olhos é chamada anteocular e a posterior pós-ocular. Na região anteocular ficam localizados o clípeo, as jugas e as genas. O rostro (aparelho bucal) é trissegmentado e geralmente curvo e a ponta repousa num sulco do prosterno. A maioria dos reduviídeos é predadora de outros insetos (com exceção da subfamília Triatominae que é hematófaga).
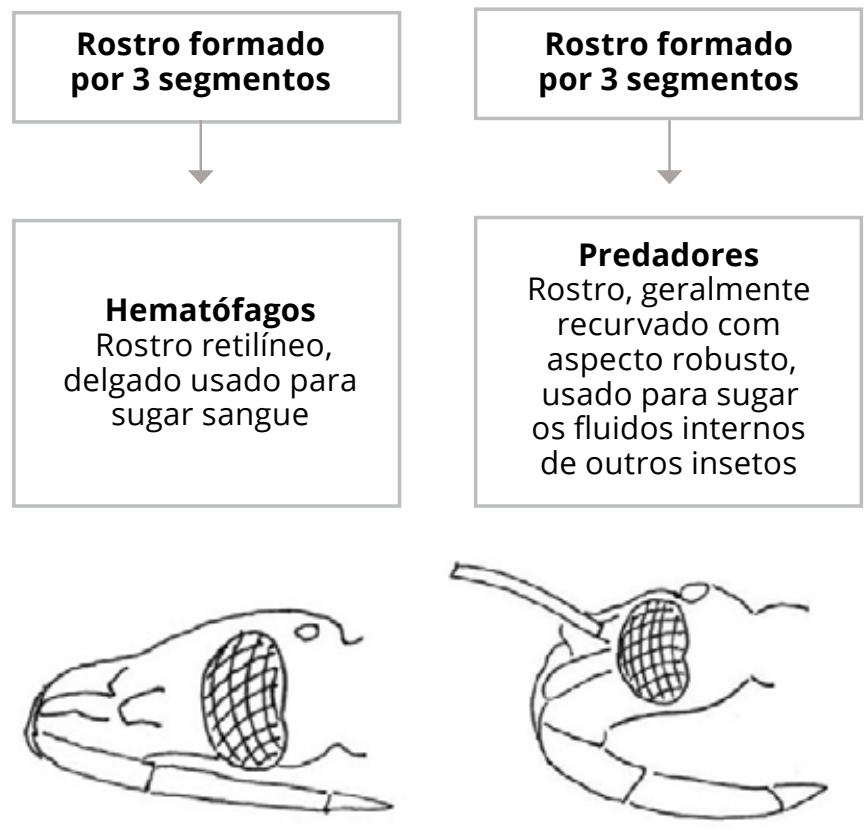

Figura 4.1: Diferenças na conformação do aparelho bucal de hemípteros hematófagos (Triatominae), predadores (Reduviidae) e fitófagos (diversas famílias).

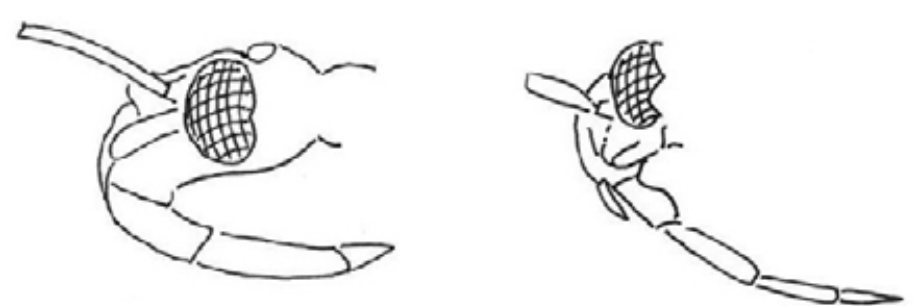

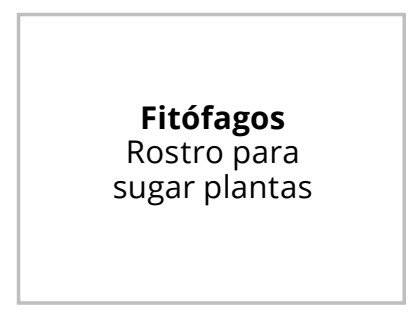
por 4 segmentos

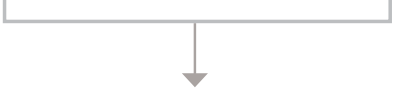

Fitófagos

Rostro para sugar plantas os fluidos internos de outros insetos
Rostro formado 
As principais diferenças entre os triatomíneos (barbeiros) e outros hemípteros terrestres (percevejos em geral) estão na morfologia e na forma de utilização do aparelho bucal. Nos hemípteros fitófagos o rostro possui quatro segmentos, enquanto que nos reduviídeos possui apenas três, sendo sempre retilíneo na subfamília Triatominae e geralmente curvo nas demais subfamílias de Reduviidae. Outra característica que pode auxiliar na diferenciação dos triatomíneos dos demais reduviídeos é o sulco transversal pós-ocular que pode ser profundo na maioria das subfamílias, pouco evidente (Triatominae) ou ausente (Phymatinae) (Figura 4.1).

A maioria das espécies de triatomíneos pode ser identificada com base em sua morfologia externa e coloração, que pode ser melhor observada nos insetos vivos ou recentemente capturados. Espécimes de coleção tendem a se tornarem mais claros ou pálidos com o passar do tempo. A aparência geral dos triatomíneos é similar à de outros reduviídeos como pode

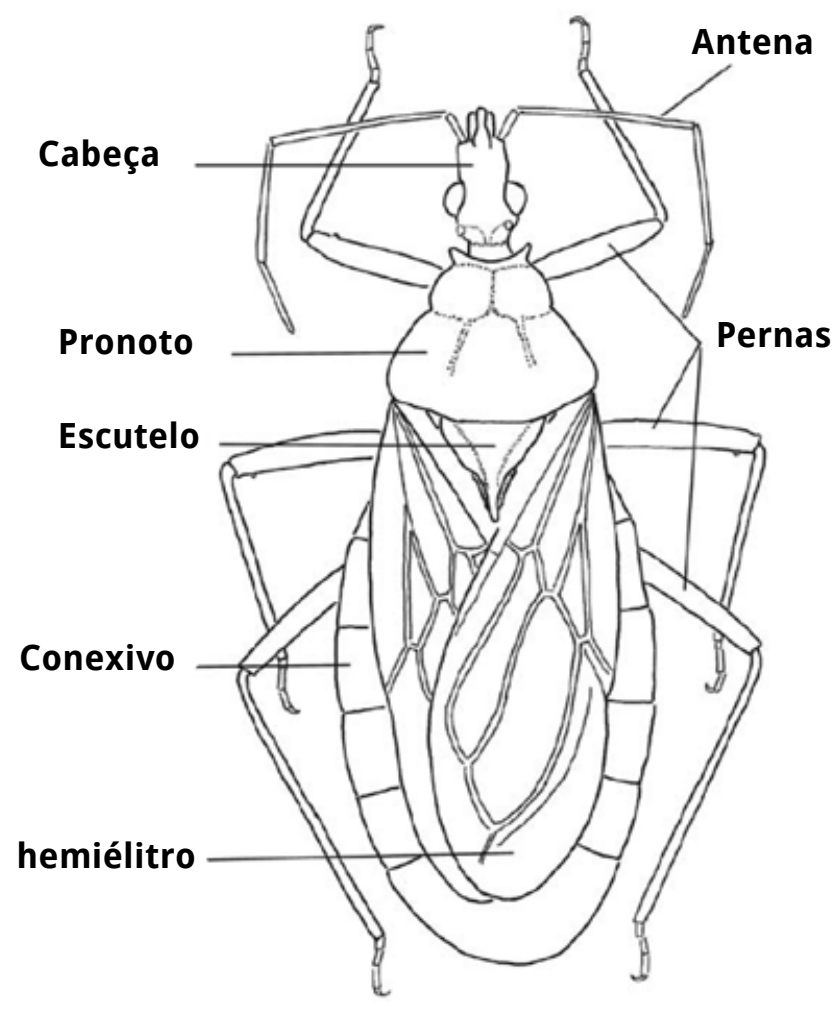

Figura 4.2: Morfologia geral de um barbeiro. ser observada na figura 4.2.

Os adultos de triatomíneos se distinguem das ninfas pela presença de ocelos, pela genitália bem desenvolvida, e com exceção das duas espécies de Mepraia (gênero que só ocorre no Chile e possui polimorfismo alar) por possuírem asas anteriores e posteriores bem desenvolvidas. $\mathrm{O}$ dimorfismo sexual está presente, ou seja, as fêmeas são sempre maiores que os machos da mesma espécie, além disso, as fêmeas apresentam o ápice do abdômen pontudo devido à presença do ovipositor, enquanto que nos machos o ápice é arredondado (Figura 4.3).

O comprimento total dos adultos varia de $5 \mathrm{~mm}$ em Alberprosenia goyovargasi até $44 \mathrm{~mm}$ em Dipetalogaster maxima, a média, entretanto, varia de 20 a $30 \mathrm{~mm}$. A coloração é útil para auxiliar na identificação, especialmente de espécimes recém mortos ou bem preservados. A coloração geral do corpo é negra ou marrom com manchas amareladas, alaranjadas, amarronzadas ou avermelhadas em várias regiões do corpo. A cor esverdeada só é vista em uma espécie: Panstrongylus rufotuberculatus. As manchas mais claras podem estar presentes em qualquer área do corpo ou apêndices, sua intensidade e distribuição tem considerável importância para propósitos taxonômicos. Variações intraespecíficas de coloração, geralmente associadas a diferentes populações geográficas não são raras, ocorrem, por exemplo, em Triatoma infestans, T. rubrovaria e Pans-

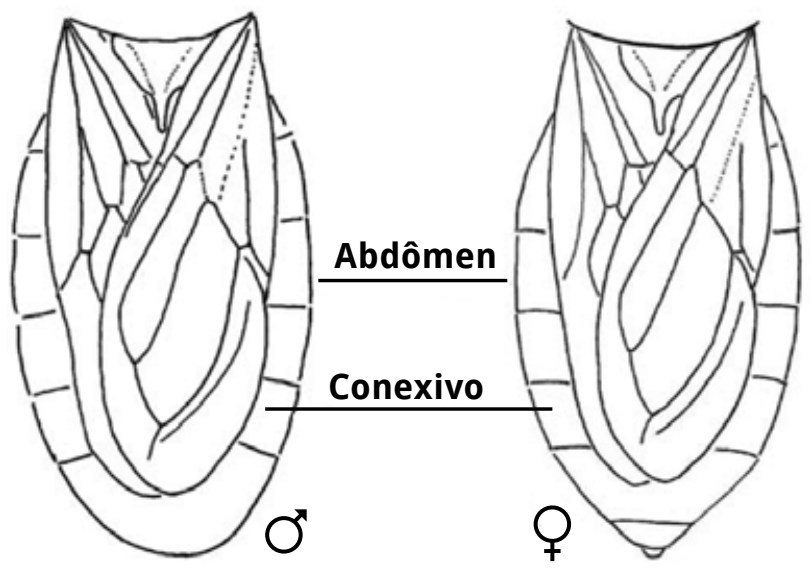

Figura 4.3: Vista dorsal do abdômen evidenciando o dimorfismo sexual. 
trongylus geniculatus. O grau de granulação ou de rugosidades do tegumento fornece caracteres úteis à identificação.

Para propósitos taxonômicos a cabeça é dividida em região anteocular e região pós-ocular e as proporções entre essas regiões são usadas nas descrições, outras estruturas da cabeça importantes taxonomicamente são o clípeo, as jugas, as genas, além do rostro e antenas (Figura 4.4).

O tórax é divido em três segmentos chamados protórax (anterior), mesotórax (mediano) e metatórax (posterior). A região dorsal de cada segmento é chamada de noto, as

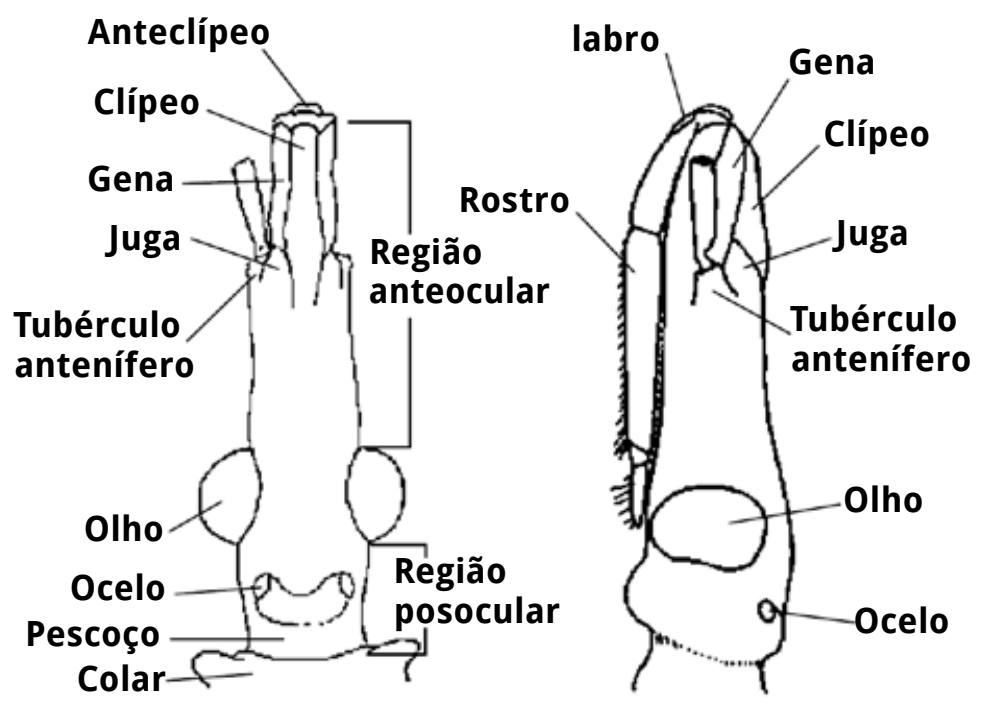

Figura 4.4: Estruturas da cabeça de importância taxonômica. laterais de pleura e a ventral de esterno. O pronoto dos triatomíneos é extremamente desenvolvido e dividido em dois lobos com diversas estruturas de importância taxonômica, logo após está localizada uma peça triangular, chamada escutelo, que se estende sobre os primeiros segmentos abdominais (Figuras 4.5, 4.6).

O abdômen é achatado dorso-ventralmente e sua borda, que conecta as faces dorsal e ventral é chamada de conexivo. $O$ conexivo apresenta manchas que são importantes para auxiliar na diferen-
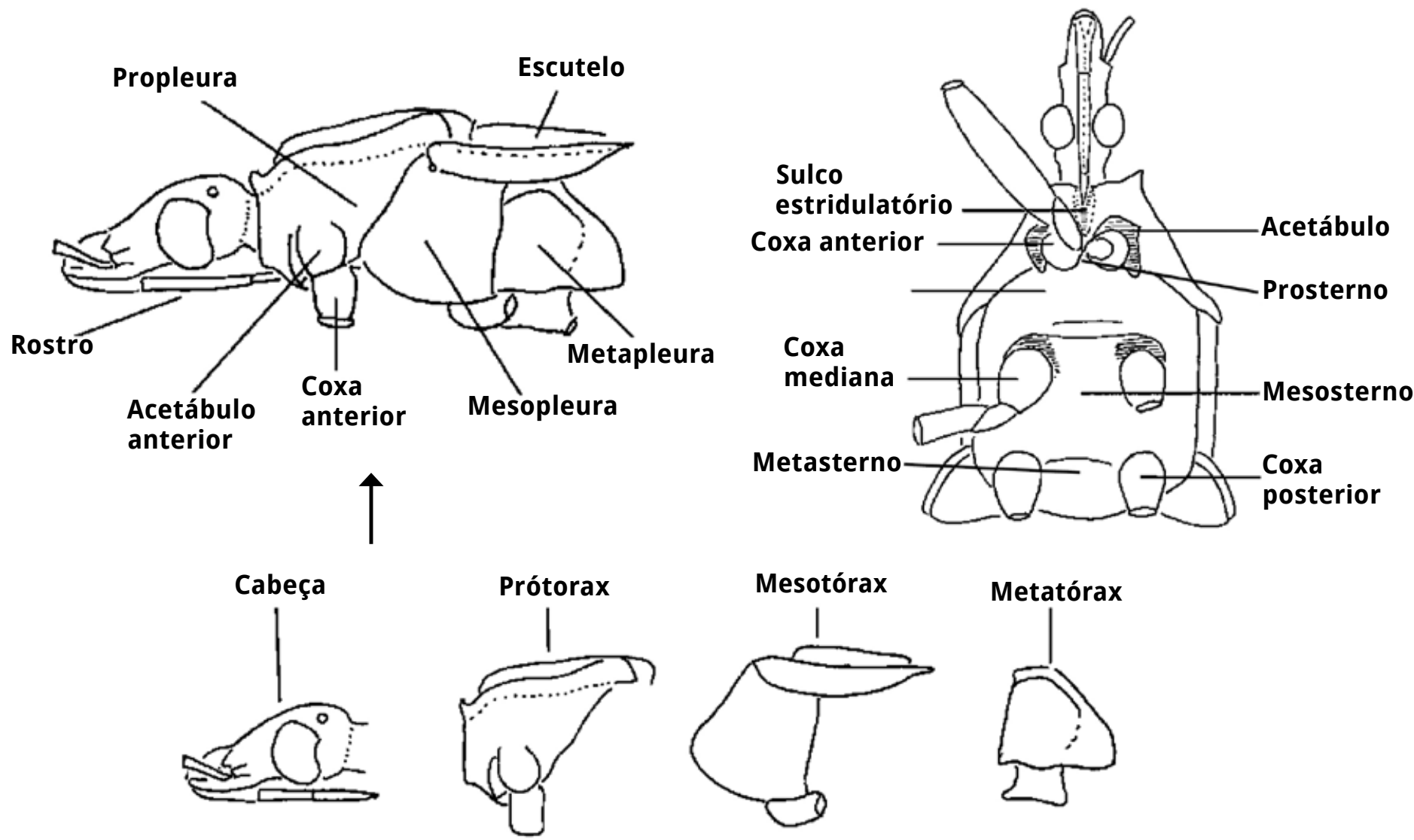

Figura 4.5: Morfologia do tórax em vista lateral e ventral. 
ciação das espécies (Figura 4.7). Entre as faces dorsal e ventral do conexivo pode existir uma membrana que permite uma maior dilatação do abdômen durante a alimentação. Essa estrutura apresenta conformações diferentes entre os gêneros (Figura 4.8). As pernas também podem apresentar anelações ou coloração úteis na diagnose das espécies.

A genitália apresenta diversas estruturas que podem ser úteis na diferenciação de gêneros e espécies. Seu estudo nos triatomíneos iniciou-se com Pinto (1926) que observou o falo, os "ganchos" (parâmeros) e a "espinha" (processo mediano do pigóforo). Posteriormente, Galliard $(1935,1936)$ ampliou

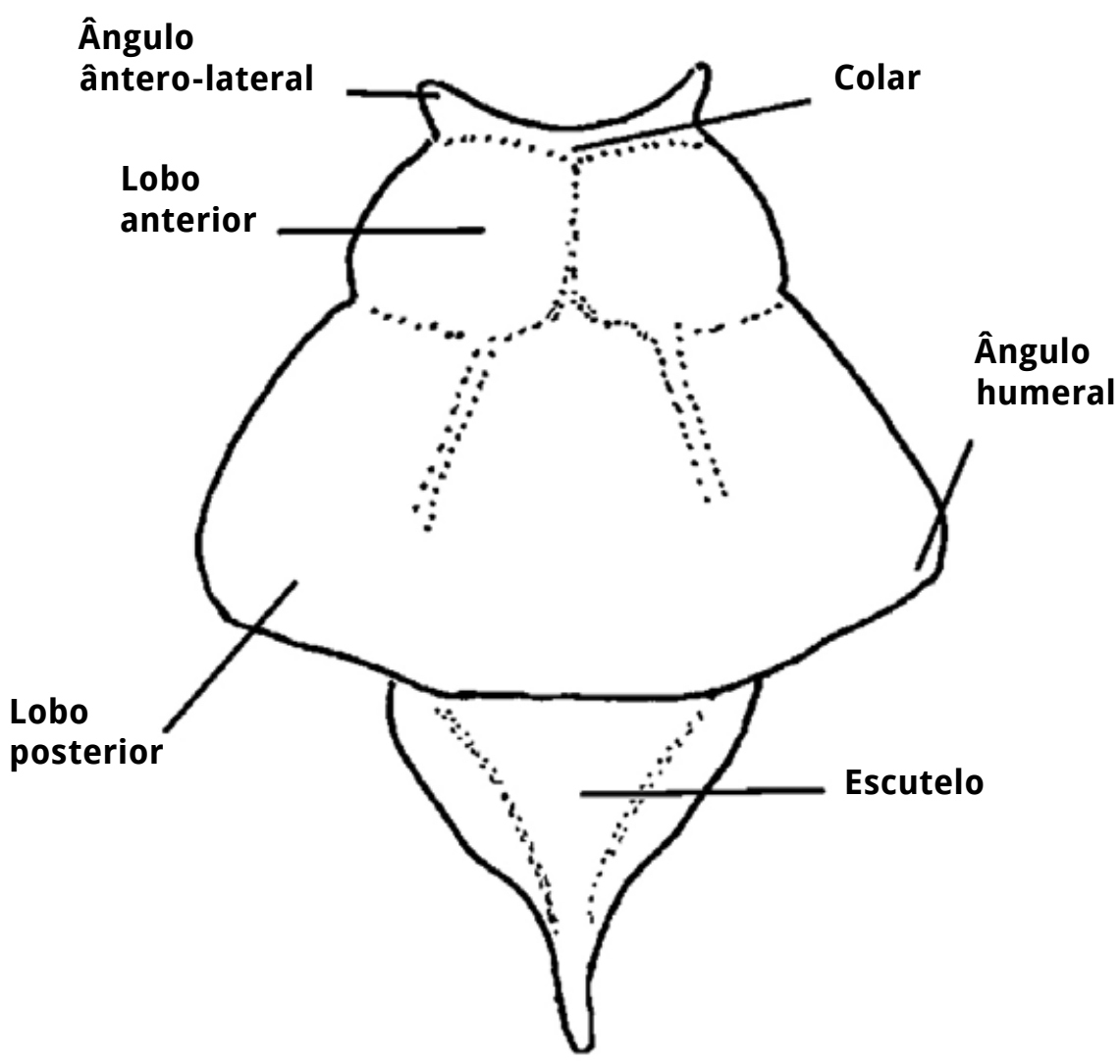

Figura 4.6: Pronoto e escutelo o estudo para as genitálias de ambos os sexos. Dupuis $(1955,1963)$ publicou uma revisão léxica, uniformizando a terminologia usada para denominar as estruturas fálicas. A partir de 1965, com os trabalhos de Lent \& Jurberg as diversas estruturas fálicas das genitálias passaram a ser analisadas comparativamente mostrando que essa ferramenta pode ser útil para auxiliar na caracterização de tribos, gêneros, espécies e até mesmo de populações (Figura 4.9, 4.10). A genitália das fêmeas não apresenta estruturas que permitam uma boa comparação entre as espécies e por isso nunca foram utilizadas. Recentemente, porém, Rosa et al. (2010) mostraram que, por meio de microscopia eletrônica de varredura, tais estruturas podem ser úteis para estudos taxonômicos.

A genitália externa dos machos é composta pelos $8^{\circ} \mathrm{e}$ $9^{\circ}$ segmentos abdominais que ficam telescopados dentro do abdômen. O nono segmento ou pigóforo é representado em quase sua totalidade pelo

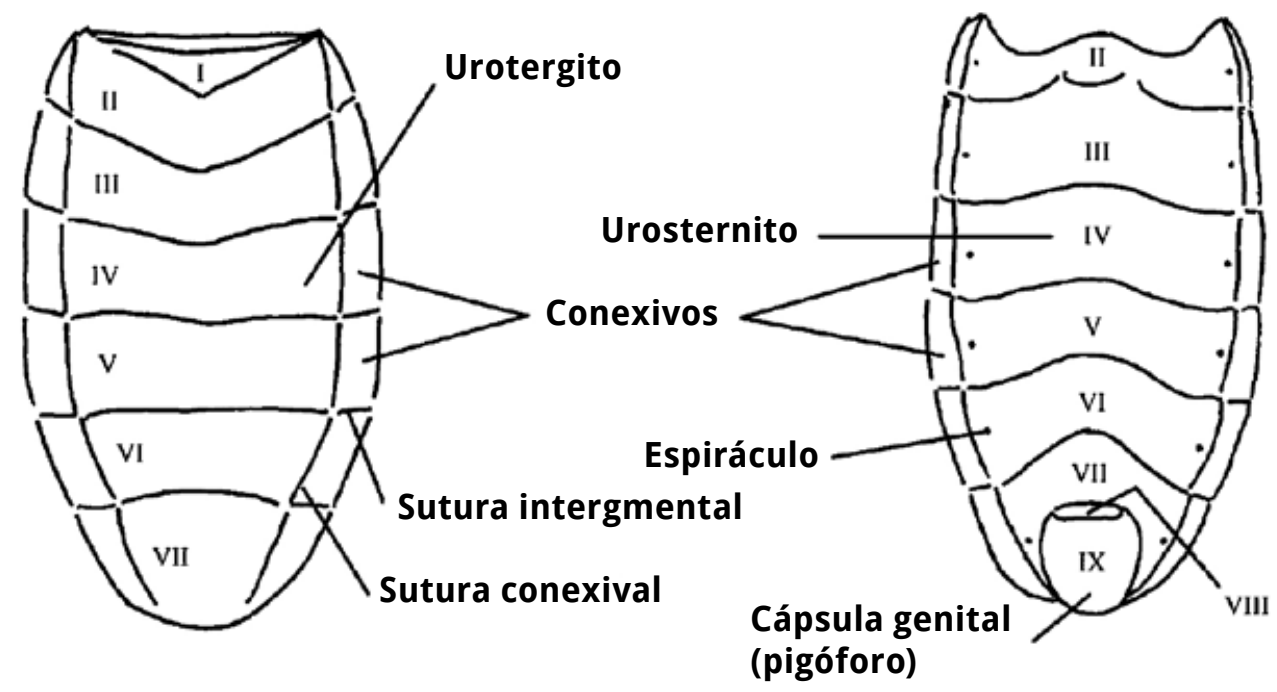

Figura 4.7: Vista dorsal (esquerda) e ventral (direita) do abdômen do macho. 
$9^{\circ}$ esternito, globoso e bastante quitinizado, o $9^{\circ}$ tergito (9t) restringe-se a uma pequena área menos quitinizada. O pigóforo caracteriza-se por possuir $1+1$ aberturas, a basal de formato circular prende-se ao $7^{\circ}$ segmento através de uma membrana elástica, e a apical caracteriza-se por estar rodeado de várias estruturas: 1+1 parâmeros $(\mathrm{Pa})$ que ladeiam a abertura genital; uma estrutura ímpar fortemente quitinizada, localizada na parte inferior da abertura genital denominada processo mediano do pigóforo (PrP), geralmente acuminada e triangular. Na parte superior está situada a abertura anal (A) tubular e membranosa, que é o $11^{\circ}$ segmento e fica dentro do $10^{\circ}$ segmento $(X)$. Dentro do pigóforo está abrigado o falo $(\mathrm{P})$, complexo composto de duas partes distintas intimamente soldadas, o aparelho articular (Apb) e o edeago (Ae). O aparelho articular é uma estrutura fortemente quitinizada
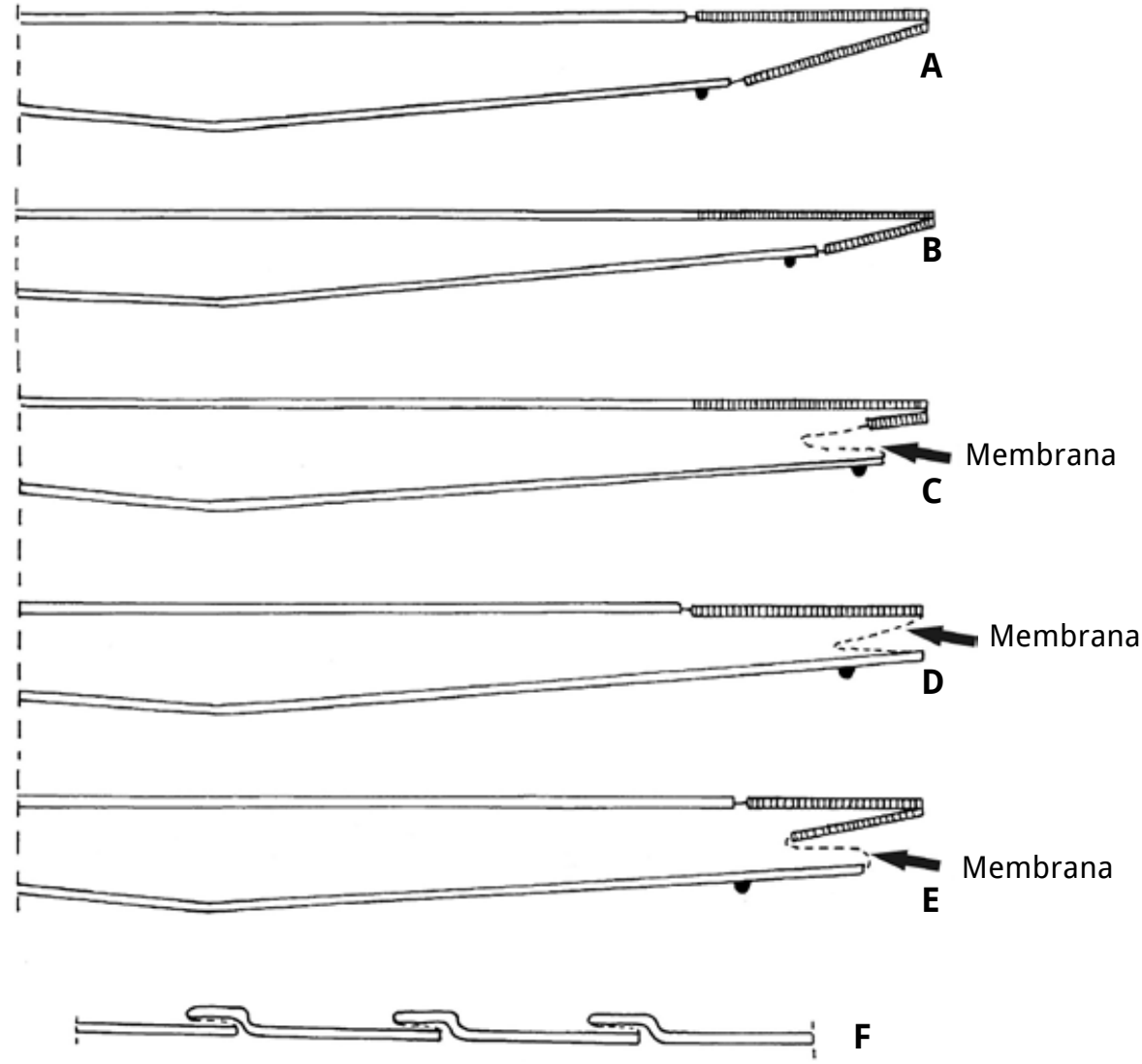

Figura 4.8: Esquema das estruturas conexivais de adultos de Triatominae em corte transversal. A: Triatoma, Panstrongylus, Eratyrus e Linshcosteus. B: macho de Mepraia spinolai. C: fêmea de Mepraia spinolai. D: Dipetalogaster maxima. E: Rhodniini, Bolboderini, Cavernicolini e Paratriatoma. F: esquema de um corte longitudinal dos urotergitos de D. maxima (espécime em jejum). (Adaptado de Lent \& Wygodzinsky 1979).

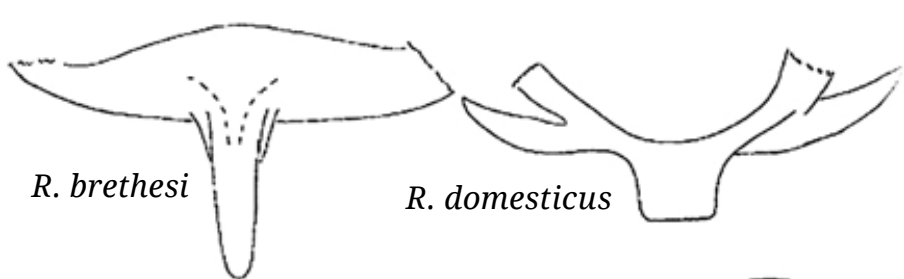

R.e.

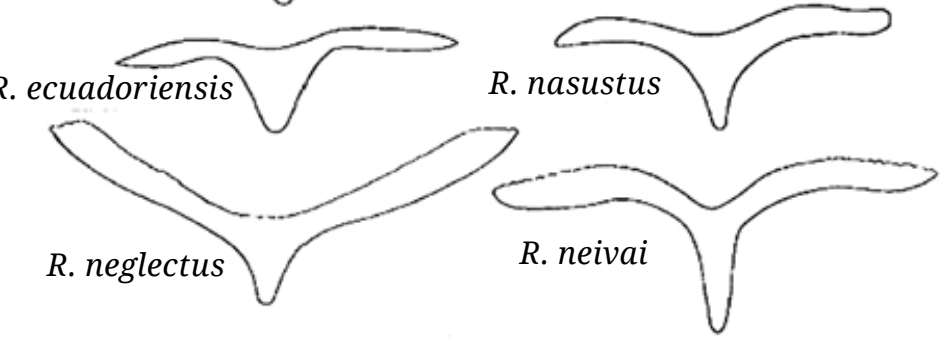

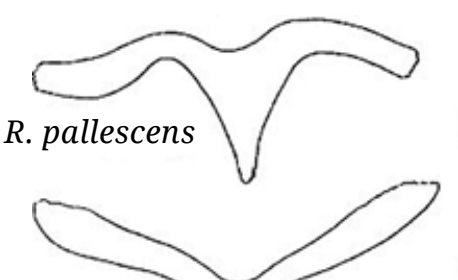

R. prolixus
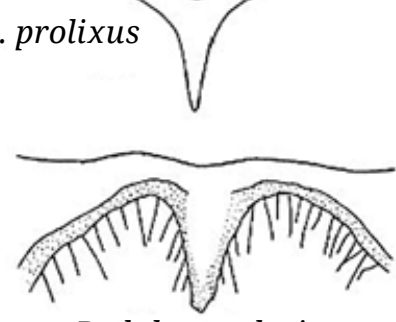

R. dalessandroi
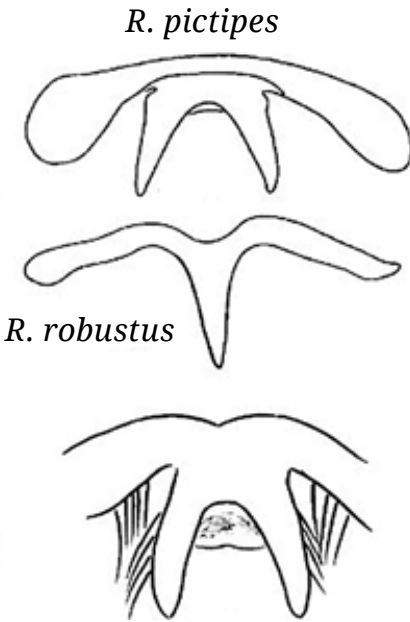

R. stali

Figura 4.9: Esquema comparativo do processo mediano do pigóforo de doze espécies do gênero Rhodnius (Reproduzido de Jurberg et al. 1998). 
na forma da letra $\mathrm{Y}$ invertida, $\mathrm{e}$ constituída por uma placa basal (Plb) tubular e dobrada, tendo na região mediana uma trave cilíndrica unindo os dois braços chamada ponte basal (PB). Na região superior, externamente unindo a placa basal ao edeago, localiza-se uma placa retangular denominada de extensão superior da placa basal (Eplb). O Edeago (Ae) é globoso e constituído de várias estruturas, a conjuntiva (Cj) membranosa que reveste a parte superior do edeago, o endosoma (En) membranoso e elástico que se everte no ato da cópula, 1+1 processos do endosoma (PrEn) laminares e pouco quitinizados e estriados longitudinalmente, a vesica (V) de formato triangular e que limita o endosoma, o falosoma (Ph) placa laminar externa bastante quitinizada que serve de assoalho ao edeago e o suporte do falosoma (SPh) uma estrutura cilíndrica de base única e braços paralelos quitinizados situados na face interna do falosoma (Figura 4.11). As estruturas fálicas podem estar presentes (+) ou ausentes (-) variando entre os gêneros da subfamília, podem ainda estar acrescidas de apêndices (Figura 4.12). Para uma melhor compreensão do tema é necessário consultar os diversos trabalhos publicados por Lent \& Jurberg a partir de 1965, entretanto, um ponto de partida pode ser a publicação de Jurberg et al. (1998b), que dá uma visão geral dessa temática aplicada a toda a subfamília.

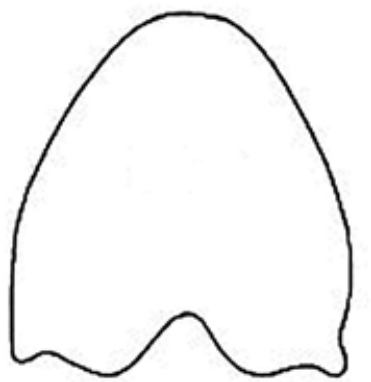

R. brethesi

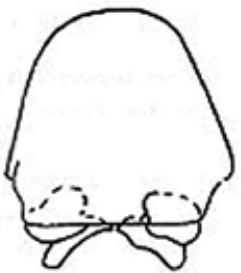

R. domesticus

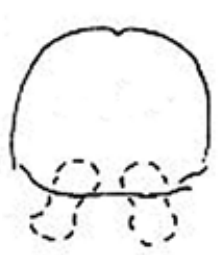

R. nasustus

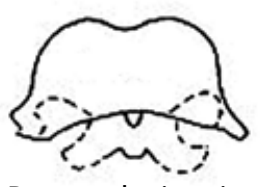

R. ecuadoriensis

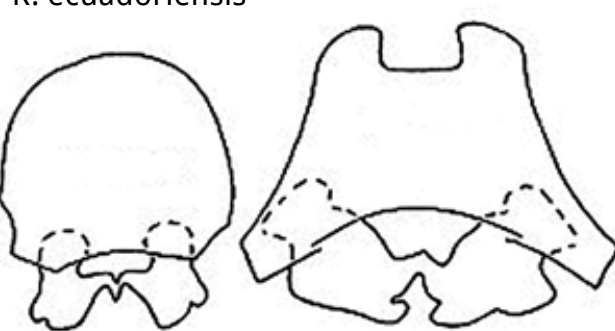

R. pallescens
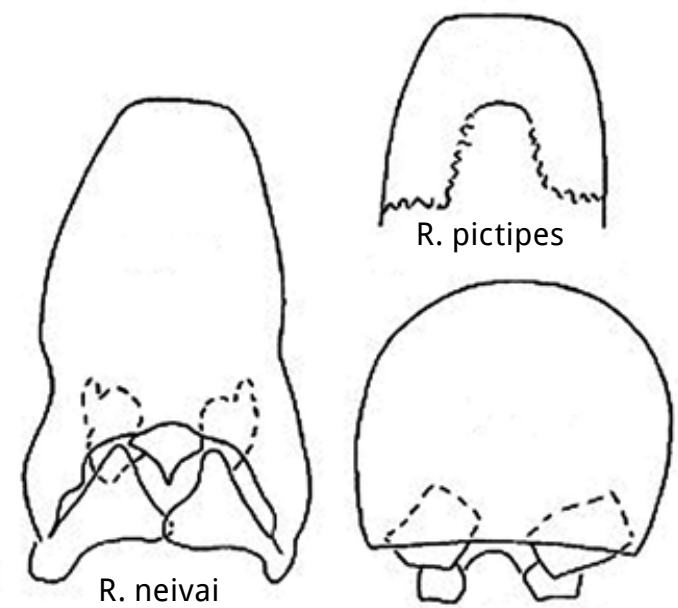

R. prolixus

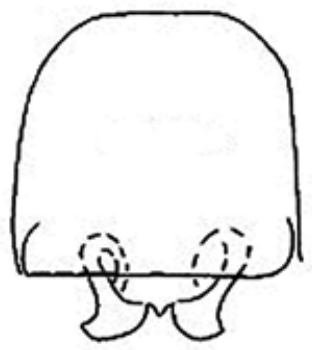

R. robustus
Figura 4.10: Esquema comparativo do falosoma de dez espécies do gênero Rhodnius (Reproduzido de Jurberg et al. 1998).
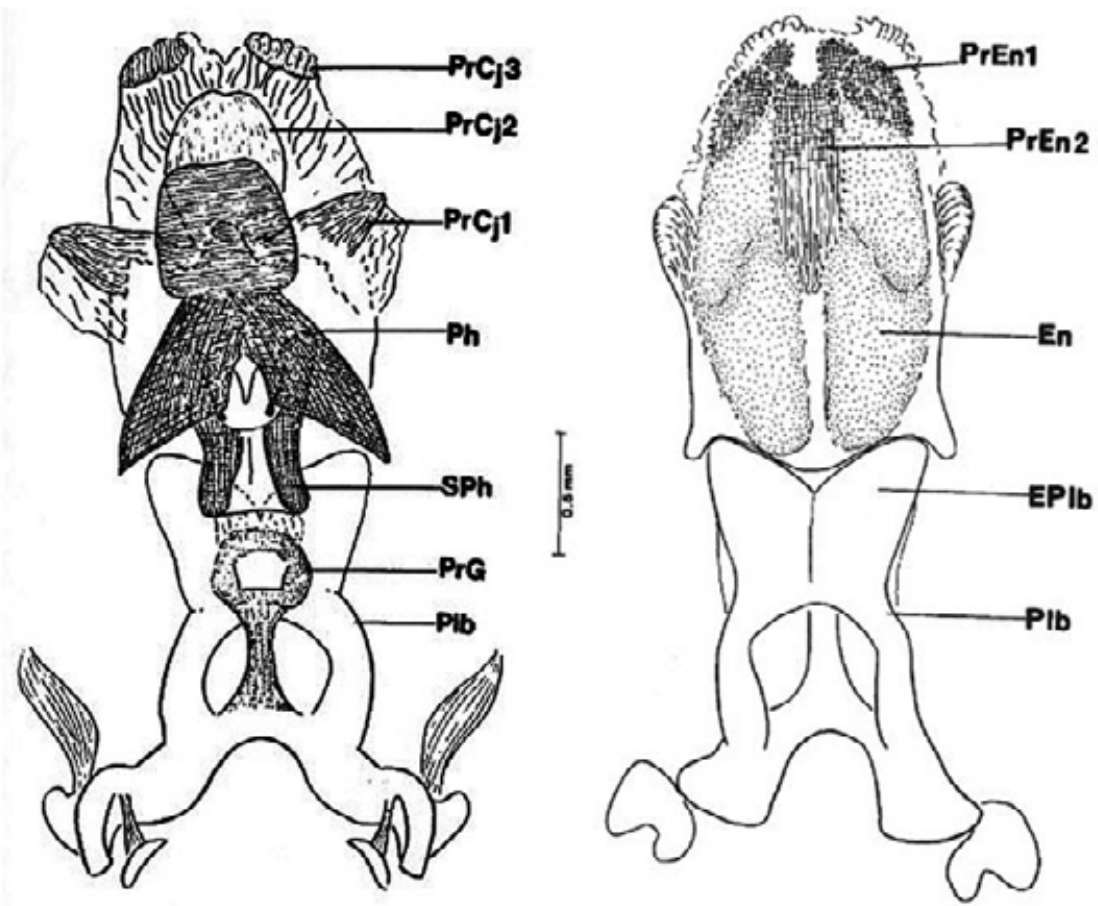

Figura 4.11: Rhodnius stali Lent, Jurberg \& Galvão, 1993. A esquerda, falo distendido em vista ventral. A direita, falo distendido em vista dorsal (En: endosoma, EPlb: extensão mediana da placa basal, Plb: placa basal, $\operatorname{PrCj}$ 1, 2, 3: processos da conjuntiva1, 2 e 3, PrEn1,2: processos do endosoma 1 e 2, Ph: falosoma, PrG: processo do gonoporo, SPh: suporte do falosoma) (Reproduzido de Jurberg et al. 1998). 


\begin{tabular}{|c|c|c|c|c|c|c|c|c|c|c|c|}
\hline & PB & PrGB & Eplb & $\mathbf{P h}$ & PrPH & SPh & PRCj & PrEn & $\mathbf{V}$ & Prp & \\
\hline Cavernicola & - & $\begin{array}{c}\text { curto } \\
+\end{array}$ & $\begin{array}{l}\text { curto } \\
+\end{array}$ & $\begin{array}{l}\text { estreito } \\
\text { curto }\end{array}$ & - & $\begin{array}{l}\text { curto } \\
+\end{array}$ & $\begin{array}{c}\text { apical } \\
\text { impar } \\
+\end{array}$ & $\begin{array}{c}1+1 \\
+\end{array}$ & - & + & CAVERNICOLINI \\
\hline Psammolestes & + & + & + & + & + & - & - & $\begin{array}{c}\text { impar } \\
\text { pequeno } \\
+\end{array}$ & - & + & \multirow{3}{*}{ RHODNIINI } \\
\hline Rhodnius & + & + & + & + & + & - & $\begin{array}{c}\text { vários } \\
+\end{array}$ & + & - & + & \\
\hline $\begin{array}{c}R . \text { stali } \\
R . \text { pictipes }\end{array}$ & + & + & + & $\begin{array}{c}\text { cone } \\
+\end{array}$ & - & + & + & + & - & $\begin{array}{c}\text { duplo } \\
+\end{array}$ & \\
\hline Triatoma & + & + & + & + & - & + & - & $\begin{array}{c}1+1 \\
+\end{array}$ & + & + & \multirow{8}{*}{ TRIATOMINI } \\
\hline Hermanlentia & + & $\begin{array}{c}\text { muito } \\
\text { longo } \\
+\end{array}$ & $\begin{array}{c}\text { muito } \\
\text { longo } \\
+\end{array}$ & $\begin{array}{c}\text { Ápice } \\
\text { digitiforme+ }\end{array}$ & - & + & $\begin{array}{c}1+1 \text { com } \\
\text { dentes } \\
+\end{array}$ & - & - & + & \\
\hline Mepraia & + & + & + & + & - & - & $\begin{array}{c}1+1 \\
\text { aliforme }\end{array}$ & - & $\begin{array}{c}\operatorname{arco} \\
+\end{array}$ & + & \\
\hline Eratyrus & + & + & + & + & - & + & - & + & + & + & \\
\hline Dipetalogaster & + & + & + & + & - & + & - & $\begin{array}{c}\text { impar } \\
\text { pequeno+ }\end{array}$ & + & + & \\
\hline Panstrongylus & + & + & + & + & - & + & - & $\begin{array}{c}1+1 \\
+\end{array}$ & + & + & \\
\hline Paratriatoma & + & + & + & + & - & + & - & $\begin{array}{c}1+1 \\
+\end{array}$ & + & + & \\
\hline Linshcosteus & + & + & + & + & - & + & - & $\begin{array}{c}1+1 \\
+\end{array}$ & + & + & \\
\hline Bolbodera & - & $\begin{array}{c}\text { muito } \\
\text { longo } \\
+\end{array}$ & $\begin{array}{c}\text { muito } \\
\text { longo } \\
+\end{array}$ & + & - & + & - & - & - & + & \\
\hline Belminus & + & $\begin{array}{l}\text { muito } \\
\text { longo }\end{array}$ & $\begin{array}{l}\text { muito } \\
\text { longo }\end{array}$ & + & - & + & - & - & + & $\begin{array}{c}\text { triangular } \\
+\end{array}$ & \\
\hline Microtriatoma & $\begin{array}{c}\text { curto } \\
\text { estrito } \\
+\end{array}$ & + & $\begin{array}{c}\text { curto } \\
+\end{array}$ & + & - & $\begin{array}{c}\text { Base } \\
+ \text { larga } \\
+\end{array}$ & $\begin{array}{c}1 \text { apical } \\
1+1 \\
+\end{array}$ & $\begin{array}{c}\text { impar } \\
\text { grande } \\
+\end{array}$ & - & $\begin{array}{c}\text { ápice } \\
\text { truncado+ }\end{array}$ & BOLBODERINI \\
\hline Parabelminus & + & $\begin{array}{l}\text { curto } \\
\text { largo } \\
+\end{array}$ & $\begin{array}{c}\text { curto } \\
+\end{array}$ & $\begin{array}{c}\text { quase } \\
\text { inaparente } \\
+\end{array}$ & - & $\begin{array}{c}\text { base } \\
+ \text { larga } \\
+\end{array}$ & $\begin{array}{c}1+1 \\
\text { apical } \\
\text { ventral } \\
+\end{array}$ & $\begin{array}{c}1+1 \\
+\end{array}$ & - & $\begin{array}{c}\text { ápice } \\
\text { truncado+ }\end{array}$ & \\
\hline Alberprosenia & - & + & + & + & - & + & - & - & - & + & ALBERPROSENIINI \\
\hline
\end{tabular}

Figura 4.12: Quadro comparativo entre as estruturas fálicas dos gêneros de Triatominae (reproduzido de Jurberg et al. 1998) 